\title{
Early Intervention for Psychosis with N-Methyl-D-Aspartate Receptor Modulators
}

\author{
Chao Dong, Kenji Hashimoto \\ Division of Clinical Neuroscience, Chiba University Center for Forensic Mental Health, Chiba, Japan
}

\section{TO THE EDITOR}

Accumulating evidence suggests that patients with schizophrenia exhibit nonpsychotic, nonspecific prodromal symptoms for several years before the onset of frank psychosis. A meta-analysis demonstrated that cognitive impairment is a common feature of the prodromal state of psychosis. ${ }^{1)}$ Accordingly, interest in the potential benefit of early intervention in psychosis is increasing. ${ }^{2-5)}$

We read the recent article by Kantrowitz et al., ${ }^{6}$ ) concerning the efficacy of D-serine (an endogenous co-agonist at the $N$-methyl-D-aspartate receptor; NMDAR) on negative symptoms in individuals at clinical high risk of schizophrenia, with great interest. In a double-blind, placebo-controlled trial, these authors compared D-serine $(\mathrm{n}=20,60 \mathrm{mg} / \mathrm{kg})$ and placebo $(\mathrm{n}=24)$ for 16 weeks. The primary endpoint was scores on the negative subscale of the Scale of Prodromal Symptoms (SOPS). D-Serine induced a significant (35.7\%) improvement in negative symptoms compared to placebo, although the number of conversions (one in the D-serine group and two in the placebo group) was too small for statistical analysis, in part due to the short duration of treatment. Nevertheless, these pilot data suggest that $D$-serine is an effective treatment of prodromal schizophrenia symptoms, despite the small sample size. ${ }^{6}$

Previously, we reported that serum D-serine levels in patients with schizophrenia were lower compared to control subjects, whereas serum L-serine levels were higher in patients than in controls. ${ }^{7,8)}$ Furthermore, we reported a reduced ratio of D-serine to total serine (DL-serine) in the cerebrospinal fluid of first-episode and drug naïve schizophrenia patients, indicating decreased NMDAR neurotransmission in the brain in early phase patients. ${ }^{9)} \mathrm{Com}$ -

Received: May 6, 2015 / Accepted: July 7, 2015

Address for correspondence: Kenji Hashimoto, PhD

Division of Clinical Neuroscience, Chiba University Center for Forensic Mental Health, 1-8-1 Inohana, Chiba 260-8670, Japan

Tel: +81-43-226-2587, Fax: +81-43-226-2561

E-mail: hashimoto@faculty.chiba-u.jp bined, these findings suggest that disturbed NMDAR neurotransmission, due to decreased D-serine levels, plays a causative role in the pathogenesis of schizophrenia. ${ }^{2)}$ In the brain, D-serine is synthesized from L-serine by serine racemase (SRR). A recent genome-wide association study confirmed the association between SRR and schizophrenia. ${ }^{10)}$ Furthermore, we reported that D-serine supplementation at between 5 and 10 weeks could prevent schizophrenia-like behavioral abnormalities in adult mice (11 weeks old) after neonatal disruption of SRR, suggesting that early intervention with D-serine prevents the onset of psychosis in adults. ${ }^{11)}$ Finally, glycine, another NMDAR co-agonist, was associated with a $10-15 \%$ reduction in negative SOPS symptoms in high-risk subjects. ${ }^{12)}$

In conclusion, given the role of NMDAR hypofunction in prodromal symptoms (e.g., cognitive impairment) and early stage schizophrenia, ${ }^{2)}$ NMDAR modulators, including D-serine, glycine, D-alanine, and sarcosine, may be effective early intervention for psychosis because they all occur naturally in humans.

\section{REFERENCES}

1. Fusar-Poli P, Deste G, Smieskova R, Barlati S, Yung AR, Howes $\mathrm{O}$, et al. Cognitive functioning in prodromal psychosis: a meta-analysis. Arch Gen Psychiatry 2012;69:562-571.

2. Hashimoto K. Targeting of NMDA receptors in new treatments for schizophrenia. Expert Opin Ther Targets 2014;18: 1049-1063.

3. McGorry PD. Early intervention in psychosis: obvious, effective, overdue. J Nerv Ment Dis 2015;203:310-318.

4. Thompson E, Millman ZB, Okuzawa N, Mittal V, DeVylder $\mathrm{J}$, Skadberg T, et al. Evidence-based early interventions for individuals at clinical high risk for psychosis: a review of treatment components. J Nerv Ment Dis 2015;203:342-351.

5. Seidman LJ, Nordentoft M. New targets for prevention of schizophrenia: is it time for interventions in the premorbid phase? Schizophr Bull 2015;41:795-800.

6. Kantrowitz JT, Woods SW, Petkova E, Cornblatt B, Corcoran CM, Chen $\mathrm{H}$, et al. D-serine for the treatment of negative symptoms in individuals at clinical high risk of schizophrenia: a pilot, double-blind, placebo-controlled, randomized parallel group mechanistic proof-of-concept trial. Lancet Psychiatry 2015;2:403-412.

7. Hashimoto K, Fukushima T, Shimizu E, Komatsu N,

(a) This is an Open-Access article distributed under the terms of the Creative Commons Attribution Non-Commercial License (http://creativecommons.org/licenses/by-nc/4.0) which permits unrestricted non-commercial use, distribution, and reproduction in any medium, provided the original work is properly cited. 
Watanabe H, Shinoda N, et al. Decreased serum levels of D-serine in patients with schizophrenia: evidence in support of the N-methyl-D-aspartate receptor hypofunction hypothesis of schizophrenia. Arch Gen Psychiatry 2003;60:572-576.

8. Yamada K, Ohnishi T, Hashimoto K, Ohba H, IwayamaShigeno Y, Toyoshima $\mathrm{M}$, et al. Identification of multiple serine racemase (SRR) $m R N A$ isoforms and genetic analyses of SRR and DAO in schizophrenia and D-serine levels. Biol Psychiatry 2005;57:1493-1503.

9. Hashimoto K, Engberg G, Shimizu E, Nordin C, Lindström LH, Iyo M. Reduced D-serine to total serine ratio in the cerebrospinal fluid of drug naive schizophrenic patients. Prog Neuropsychopharmacol Biol Psychiatry 2005;29:767-
769.

10. Schizophrenia Working Group of the Psychiatric Genomics Consortium. Biological insights from 108 schizophreniaassociated genetic loci. Nature 2014;511:421-427.

11. Hagiwara H, Iyo M, Hashimoto K. Neonatal disruption of serine racemase causes schizophrenia-like behavioral abnormalities in adulthood: clinical rescue by $d$-serine. PLoS One 2013;8:e62438.

12. Woods SW, Walsh BC, Hawkins KA, Miller TJ, Saksa JR, D'Souza DC, et al. Glycine treatment of the risk syndrome for psychosis: report of two pilot studies. Eur Neuropsychopharmacol 2013;23:931-940. 